\title{
Logistic development and use of personnel motivation system based on the chosen strategy of sports organization
}

\author{
Olga Kalinina ${ }^{1, *}$, Valery Suschenko ${ }^{1}$, Valery Shchegolev ${ }^{1}$, and Sergey Barykin ${ }^{2}$ \\ ${ }^{1}$ Peter the Great St. Petersburg Polytechnic University, Polytechnic Str., 29, 19525, Saint-Petersburg, \\ Russia \\ ${ }^{2}$ Selectel Ltd., Head of Internal Audit, Ul. Tsvetochnaya 21, lit. A, St. Petersburg, 196084, \\ Russia
}

\begin{abstract}
Logistical approach to the organization system of sport events results in forming new theoretical concept in the specific field regarding the social, economic and political spheres. The study of literature sources suggest the origins of sports events could be seen in models formed in flows of information and participants of contests. The idea of flow concept should be considered as a new approach with some features which played a progressive and positive role in the development of the world community. At present, the modern system of sports events is a complex industry that has global significance in economic, social, technological and political relations. The subjects of management of this kind of sports events, as a rule, are several categories of participants. First of all, these are the athletes who are the main characters in the competitions. In addition to them, managers, sports judges, coaches, medical personnel, representatives of the mass media, service personnel, sponsors, representatives of administrative bodies, spectators, etc. participate in the organization and management of sport events themselves.
\end{abstract}

\section{Model of the system of key productivity indicators in the management of sports activities of the university}

Professor Ilin considers IT Solution concept development for tracking and analyzing the labor effectiveness of employees [1] which could be treated as a logistic approach from the global point of view. Based on the methodology of the system approach, it is advisable to combine all the variety of sports events held in educational institutions of higher education in two categories. The first one includes sports activities held in accordance with the approved plans for sports events of the university in the form of internal sports competitions in various sports [2-3].

Another category is sports events, where they are considered as a set of separate independent competitions in the sports, regulated by the plans of external sports competitions

\footnotetext{
*Corresponding author: olgakalinina@bk.ru
} 
for the championship of higher education institutions of the country, region, international sports events with the participation of students of this or that university.

Let us turn to the wide-known Balanced Scorecard, developed on the basis of a study conducted in the early 1990s. professor of the Harvard Business School R. Kaplan and president of the consulting firm "Renaissance Solutions" D. Norton (for more details, see [11]). The technique refers to the target management of P. Drucker and the method of describing the links between goals using "smart maps", developed by T. Bucin.

It is advisable to start the development of a system of indicators for operating in the sports management of an educational institution with the development of a tactical plan for the activities of the department responsible for the sports achievements of the institute.

1. Develop a program to attract human resources (student athletes, talented teachers, trainers, doctors, instructors, etc.)/

2. Develop a program for financing activities, coordinate with the administration, financial directors, and interact with the strategy and mission of the institution.

3. Implement a program plan for attracting talented students with financial and information support to the administration of the educational institution.

4. To motivate students, teachers, trainers to achieve high results.

5. To take part in interuniversity competitions, in prestigious competitions of a different level, to provide assistance for the participation of individual successful students in various competitions according to their individual plan for implementing sports achievements, etc.

6. Conduct PR-events, advertise the activities of the department, the achievements of students, the conditions of work of teachers, coaches, a creative democratic socially-directed atmosphere of the institute, programs to promote personal and collective achievements of student athletes and employees.

With a large functional of the department, it is advisable to form a separate unit of responsibility and business unit of the universal contribution to the financial well-being and the atmosphere of prosperity and development of the educational institution. Тактический план деятельности отдела является основой создания системы сбалансированных показателей деятельности отдела.

Indicators responsible for the sporting achievement, for participation in sporting events, which were appropriately weighted by the expert method of assessment, can be selected by the main KPI in accordance with the chosen strategy.

According to Vikhansky the term strategy stands for a certain direction of development, leading the organization to its goals [10]. The sphere, means and forms of activity, the internal environment and the position of the company in the external environment are subject to this direction of development.

Educational institutions, where there is a shortage of students, where specialties are taught, which for obvious reasons are considered not prestigious, not highly paid, not attractive from the point of view of social preferences, must be exerted an enormous effort in order to find a way out of this socially significant education system problem.

To attract qualified employees and talented students, it is necessary to develop strategic planning with the involvement of environmental and social programs for the development of the educational institution. In the mission of the educational institution, in addition to basic educational and educational activities, health, spiritual and social aspects can be prescribed.

Socially significant motivation of sports achievements among students of educational institutions can be the object of scientific knowledge and application in order to raise the prestige of educational institutions, increase the influx of students and in particular talented and successful students in sports.

Proceeding from these theses, it is possible to outline the strategic plan for the management of sports activity of the university. Management of sports activities, as an object of scientific knowledge in this case, can learn and apply methodologically proven 
management concepts and operational management models that are widely accepted and effective in other areas of activity.

According to the ideology of the KPI, the system of stimulating students, coaches, sports doctors is directed to the following directions:

- managing the motivation for achievements;

- To stimulate the best results to achieve the goals in accordance with the company's strategy;

- increasing the personal and team performance of all student athletes;

- attracting and retaining employees in the sporting field of activity;

- positioning of an educational institution (institute, university, academy) with high performance indicators of sports activities as an educational institution with an attractive social-oriented, health-improving program and an atmosphere of all-round support for business, scientific and sports activities, etc.

Key performance indicators for the sports department of the school serve to assess the achievement of goals. The indicators of KPI are mainly considered in dynamics in relation to the previous period.

The list of indicators is exemplary and can be flexibly reconfigured in case of any external and internal changes.

\section{Logistics concept of management of sports activities of an educational institution}

According to the opinion of Ilin one could consider measurement of enterprise architecture from an IT perspective [4] and develop such approach considering the universities where individual, team sports implementation is actively supported, as scientifically managed towards the motivation of talented students and the motivation of sports coaches for the effectiveness of this type of activity. The logistic concept of management of sports activities of educational institutions, methods of achieving sports results in the process of information, material, financial flows set the goal of developing sports activities of educational institutions:

- attracting human resources;

- increasing the flow of entrants;

- individual sports development of students;

- achieving high sports performance of students and employees;

- sports development of the work collective;

- enhancing the prestige of the university.

Talents ensure the achievement of higher results, which in turn bring worthy compensation, which attracts new talents, which allows creating a serious long-term effect of cultural changes, which has a positive impact on the activity of the institution, strategy and competitiveness. In the future, it is possible to improve the motivation system under consideration and broadcast it to all divisions in order to improve the management efficiency of the educational institution as a whole (see Fig. 1). 


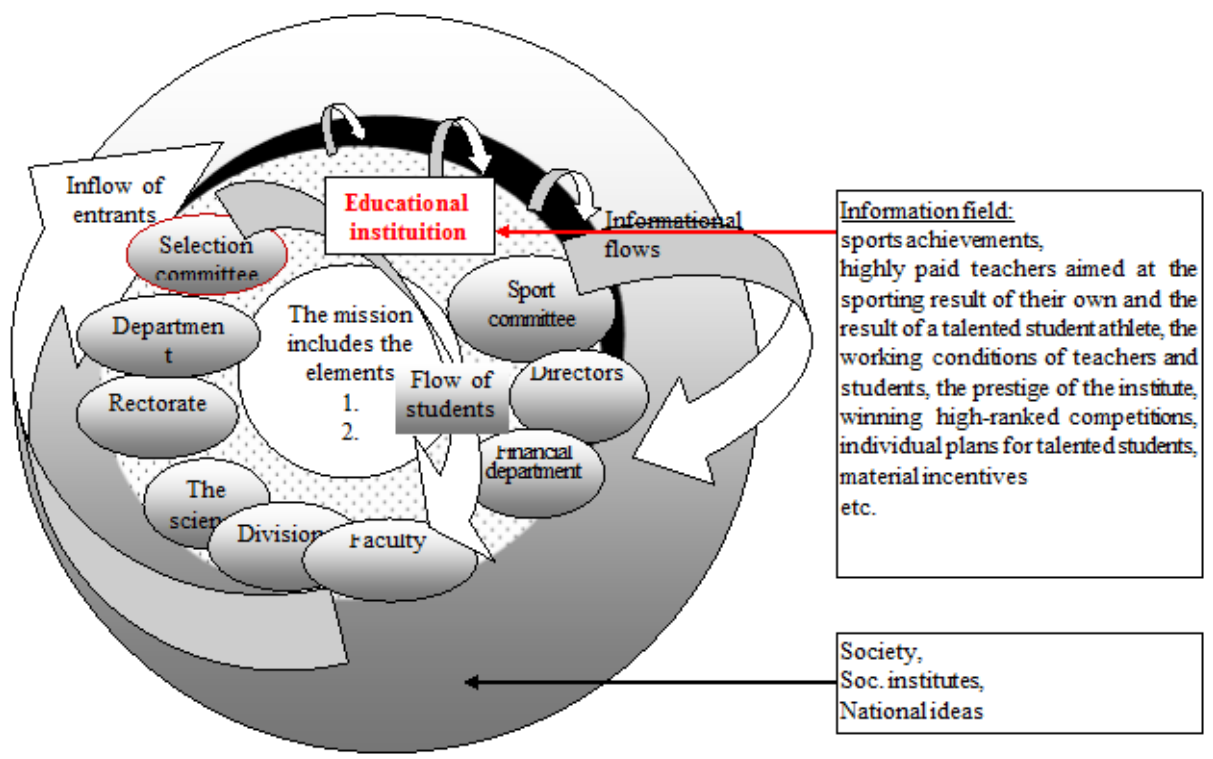

Fig. 1. Flows of information and students in the system of personnel management in the field of sports activities of the university.

In an educational institution, logistical flows have the specificity of an inseparable link with society and social institutions, ideas of national well-being, with economic and energy resources, human and information resources. Due to these socially-directed connections, financial inflows for the implementation of strategic goals can have the most unexpected sources. The authors do not set out the task of concretizing the sources of financial support for sports activities of educational institutions in this article.

\section{Decomposition of financial support for sports events}

In determining the leading factor or criterion that forms the system of financing sports events, in our opinion, a priority ranking approach is necessary, which could become a common direction ensuring the communicative effectiveness of sporting events and their hierarchical construction. Sport activities with students as an object of management are characterized as dynamic systems, since they function under conditions of variability of various factors of the external environment, as well as changes in their internal states under the influence of these factors. On the scale of the subject of management of sports events, several levels can be identified in relation to the aspect of this study: state, departmental, university, personal [57]. The state level of management of sports events affects the entire sports industry and the system of sports training as a factor of their purposeful influence on the personality of the athlete, where society as a whole acts as a subject of sports and pedagogical influence.

The departmental level provides management of sports activities in sports organizations (sports clubs, universities, federations, etc.).

The university level characterizes the ways of direct individual or group influence on the personality of a student-athlete or a student sports team on the part of a coaching or teaching staff. The personal level of management of sports activities aimed at sports improvement of students means management in which the subject and the object of training influence can be the same person, i.e. himself a student-athlete [8-9]. To achieve a global goal that has a complex structure of multi-criteria optimization of financing, one can take into account qualitative differences in the objective functions. Within the framework of the decomposition 
of the problem of managing the financing of sports events, we will distinguish three levels: the level of priority directions, the level of criteria, the level of the directions of development of sports activities. The decision can be made by a private investor, the financial department of an educational institution, the financial department of the Ministry of Education and Science, the finance departments of branch departments, etc.

\section{Conclusion}

In the course of sporting events with students, the process of improving their sports skills is carried out in the conditions of modification of organizational and management goals and the emergence of new tasks, the constant updating of management information, on the basis of which new content, new forms and methods of preparation for sporting events of various scale are formed. Sporting events held in the conditions of the university have their own specific features that must be taken into account when managing educational sports systems. In the context of this study, this aspect is of fundamental importance, since athletes with a certain level of sporting achievements and experience in sports activities act as the object of sports perfection. The development of effective systems of strategic management becomes one of the priorities of the educational institution. The effectiveness of strategic management and its successful implementation requires the involvement of all employees of the organization in this process. Currently, in a number of countries (the United States, Britain, France, etc.) the training, testing and introduction into the practice of training are implemented in new educational programs for the preparation of bachelors and other specialists in the management of sporting events.

In conclusion, it should be noted that the popularity of sports events has led to increased commercial interest and greater competition in this area, which in turn has led to the need for optimization and concentration of financial resources in the management of the sports movement in order to remain within the framework of social standards and values

\section{References}

1. I. Ilin, S. Shirokova, A. Lepekhin, E3S Web of Conferences 33 (2018)

2. A.Bolotin, V. Bakayev, Theory and Practice of Physical Culture 1, $72-88$ (2018)

3. N.N. Vengerova, L.V. Lyuik, O.E. Piskun, Theory and Practice of Physical Culture 6, 57-59 (2016)

4. I. Ilin, A. Levina, A. Abran, O. Iliashenko, ACM International Conference Proceeding Series F131936, 232-243. (2017)

5. A.E. Bolotin, O.E. Piskun, S.N. Pogodin, Theory and Practice of Physical Culture 3, 5153 (2017)

6. A.Bolotin, V. Bakayev, Journal of Human Sport and Exercise 3,607-615 (2017)

7. L.V. Yarchikovskaya, V.N. Kovalenko, O.V. Mironova, A.V. Tokareva, O.N. Ustinova, Theory and practice of physical culture 2, 82-87 (2018)

8. S.N. Pogodin, O.E. Piskun, V.I. Samorukov, Theory and practice of physical culture 4, 96-98 (2018)

9. V. Bakayev, V. Vasilyeva, S. Kalmykova, E. Razinkina, Journal of Physical Education and Sport 1, 293-297 (2018)

10. O.S. Vikhanskiy, Strategic management: a textbook (The Economist, Moscow, 2006)

11. D. Norton, R. Kaplan, Balanced Scorecard. From strategy to action (ZAO OlimpBusiness, Moscow, 2010) 